\title{
GOBIERNO CONDUCTUAL: NUDGES, CAMBIO DE COMPORTAMIENTO INCONSCIENTE Y OPACIDAD
}

\author{
David Arellano Gault \\ E. Fernanda Barreto Pérez
}

\section{INTRODUCGIóN}

Diversos AUTORES HAN NOTAdo que frecuentemente surgen, en las disciplinas de la administración y las políticas, corrientes de pensamiento que se caracterizan por tener nombres llamativos como estrategia para llamar la atención, más allá de la solidez de los supuestos y las evidencias que las sostienen. Es por ello que en algunos contextos se los ha denominado "modas administrativas". ${ }^{1}$ Se los pueden llamar modas debido a que se posicionan por medio de discursos y retóricas como soluciones relativamente integrales a grandes problemas de la gestión o de las políticas públicas. ${ }^{2}$ En este sentido, en los últimos años han surgido diversas de estas modas conocidas por ciertas etiquetas que las identifican como un todo congruente, si bien muchos dudan que en realidad sean un conjunto integrado de conocimientos y herramientas. Entre las

${ }^{1}$ Christopher Pollit, "Justificactions by Work or by Faith: Evaluating the New Public Management”, Evaluation, vol. 1, núm. 2, 1995; Harry Hatry, Performance Measurement: Fashions and Fallacies, Public Performance and Management Review, vol. 254, núm. 4, 2002, pp. 352-358; Brad Jackson, Management Gurus and Management Fashions, London, Routledge, 2001; Lynn, Laurence Jr., Public Management: Old and New, Nueva York, Routledge, 2006.

${ }^{2}$ Nils Brunsson, Mechanisms of Hope. Maintaining the Dream of the Rational Organization, Copenague, Copenhagen Business School Press, 2006; Nils Brunsson y Johan Olsen, The Reforming Organization, Oslo, Fagbokforlaget, 1993. 
más famosas están a la nueva gestión pública, ${ }^{3}$ la evaluación del desempeño y por resultados, ${ }^{4}$ las políticas públicas por evidencias, ${ }^{5}$ redes de políticas públicas, ${ }^{6}$ la gobernanza democrática, por proximidad o pluricentrista, ${ }^{7}$ entre otras.

En esta lógica se puede decir que una nueva moda se está posicionando en el ambiente de la gestión y las políticas públicas. Sus bases, campeones, apologistas y experimentadores se encuentran listos, en diversas arenas académicas, gubernamentales y de organismos internacionales, para tomar la delantera. Esta nueva moda, que por lo pronto llamaremos de gobierno conductual, es una extraña combinación de neurociencias, psicología evolutiva y economía conductual.

En el presente artículo se presenta, primero, una revisión de los supuestos básicos y los argumentos centrales de esta corriente del gobierno conductual. Después se discute una de las críticas centrales que se están realizando a esta corriente: su falta de transparencia y los riesgos de permitir a una autoridad política como lo son los gobiernos diseñar instrumentos que buscan manipular o afectar el comportamiento inconsciente de las personas.

Para poner en claro estos objetivos, se puede comenzar con un apretado resumen de su argumento central de la idea del gobierno conductual. Éste podría ir más o menos así: los seres humanos y sus relaciones, organizaciones e instituciones no son ni pueden ser agentes o colectividades enteramente racionales. Al contrario de lo que teorías como el modelo clásico de la economía han supuesto, el comportamiento de los seres humanos y de sus organizaciones e instituciones son resultado de procesos sociales que se auxilian constantemente de heurísticas de racionalidad limitada.

${ }^{3}$ Michael Barzelay, Breaking through Bureaucracy, Berkeley, University of California Press, 1992.

${ }^{4}$ Peter Smith, Measuring Outcome in the Public Sector, Exeter, Taylor \& Francis, 1996.

${ }^{5}$ Nancy Cartwrite y Jeremy Hardie, Evidence-Based Policy: A Practical Guide to Do It Better, Oxford, Oxford University Press, 2012.

${ }^{6}$ Hugh Compston, Policy Networks and Policy Change: Putting Policy Network Theory to Test, Nueva York, Palgrave, 2009.

${ }^{7}$ Luis F. Aguilar, Gobernanza y gestión pública, México, FCE, 2006. 
Estas heurísticas $^{8}$ no buscan ni pretenden construir comportamientos óptimos, sino que constituyen una estrategia más delicada: construir prácticas, hábitos o rutinas que acotan (mental y socialmente) la incertidumbre que las personas y los grupos enfrentan al tomar decisiones, justamente para que, pese a la irreductible incertidumbre, puedan tomar decisiones. Y en efecto funcionan de esa manera. Pero en determinadas circunstancias estas heurísticas producen efectos negativos, tanto para los individuales como para los grupos e incluso a la sociedad en general. Esta paradoja -según este resumen sobre la idea del gobierno conductual-se debe a que al final de cuentas los seres humanos son seres biológicos en primera instancia, por lo que no pueden escapar tan fácilmente de ciertos parámetros (físicos y mentales) que nuestra adaptación ha generado durante millones de años de evolución.

Lo anterior sería entonces un apretado resumen de los supuestos de esta corriente que denominamos gobierno conductual. A partir de estos supuestos, se asume una hipótesis de acción: corregir los "errores" de racionalidad no puede ser una empresa completamente racional. El cerebro no es un órgano creado racionalmente, por diseño digamos. La evidencia parece indicar que no hay un centro de cálculo ni una zona del cerebro que construya sintéticamente la voluntad. La voluntad, el libre arbitrio -de existir-, es una producción de múltiples partes del cerebro en comunicación y en competencia. ${ }^{9}$ Las sociedades humanas son construcciones de estos cerebros de racionalidad limitada. Las estrategias heurísticas, que han sido tan útiles a la especie humana a lo largo de siglos, están ya claramente incrustadas en los sistemas automáticos de comportamiento que ayudan a las personas a enfrentar la incertidumbre. Corregir esas heurísticas cuando no funcionan no puede ser logrado siempre invocando a la voluntad o a la racionalidad de la persona, pues muchos de estos procesos son inconscientes; están ocultos a la voluntad de la

${ }^{8}$ Simon, Herbert, Administrative Behavior, Chicago, Chicago University Press, 1947; Gerd Gigerenzer, Gut Feelings: The Intelligence of the Unconscious, Nueva York, Penguin, 2007.

${ }^{9}$ Jonah Lehrer, How We Decide, Boston, Mariner, 2009. 
persona misma. ${ }^{10}$ La "gestión de la mente", ${ }^{11}$ por seguir esa llamativa metáfora, requiere construirse con otras lógicas. Se pueden crear nuevas heurísticas, lanzar estrategias de aprendizaje que sepan aprovechar esos espacios automáticos - para que cambiando esas estrategias heurísticas se ajusten de modo que los seres humanos sean capaces de adaptarlas-, y tal vez aprenderlas y racionalizarlas.

Para ello, entonces, no serán siempre los instrumentos racionalizadores los que apoyen estas labores, sino tal vez otro tipo de instrumentos, más humildes y pequeños: los “empujoncitos”. Nudges, en inglés, son ligeros codazos, pequeños empujones, donde actores como el gobierno, basados en un "paternalismo libertario", ${ }^{12}$ dejen la decisión última a las propias personas, pero ayudándoles a descubrir y corregir (así sea inconscientemente) esas heurísticas que a veces las hacen actuar en contra de su propio bienestar. Es libertario porque se asume que la libertad de las personas es, en última instancia, fundamental y que ningún gobierno puede legítimamente definir lo que sus ciudadanos consideran correcto o adecuado de hacer. $\mathrm{Y}$ es paternalista porque, comprendiendo las limitaciones y lógicas neurobiológicas y sociales del comportamiento, se puede auxiliar a los seres humanos a que corrijan los errores más comunes que sus sistemas automáticos de respuesta están acostumbrados a construir como reacciones automáticas o semiautomáticas. De ahí los nudges, los empujoncitos: la construcción de una arquitectura de decisión pública que aprovecha las fuerzas conscientes e inconscientes que nuestros cerebros han constituido biológica y socialmente para actuar con velocidad en un mundo intrincado, pero que también pueden traicionarnos y hacernos actuar inadvertidamente en formas irracionales o perniciosas para nosotros mismos.

El gobierno conductual es, entonces, uno que sabe aprovechar estas fuerzas irracionales e inconscientes, creando marcos de arquitectura de decisiones que ayudan a las personas a tomarlas

${ }^{10}$ Daniel Dennett, Freedom Evolves, Nueva York, Penguin Books, 2003.

${ }^{11}$ Nikolas Rose y Joelle Abi-Rached, Neuro: The New Brain Sciences and the Management of the Mind, Princeton, Princeton University Press, 2013.

12 Richard Thaler y Cass Sunstein, Nudge: Improving Decisions about Health, Wealth, and Happiness, Nueva York, Penguin Books, 2008. 
de mejor manera, sin necesariamente restringir su comportamiento de forma arbitraria desde el propio gobierno.

Las implicaciones sociales y políticas de la corriente de los nudges apenas se están vislumbrando. Gobiernos de países como el del Reino Unido, ${ }^{13}$ más que ningún otro, y el federal de los Estados Unidos ${ }^{14}$ se están sumando a estas ideas y están experimentando con sus modelos. Desde luego, las respuestas y críticas a la propuesta no se han dejado esperar a la luz de sus resultados y potenciales problemas sociales y humanos devenidos de la implementación. ${ }^{15}$ Ahora, parece un buen momento para realizar un análisis crítico de estas ideas y de sus propuestas, con el fin de abrir el debate de manera amplia. En este sentido, este artículo busca realizar tanto un resumen de los principales supuestos teóricos y analíticos que sustentan esta corriente de reforma gubernamental, y hacerlo a través de la lente de una de las críticas más severas que se le oponen: la falta de transparencia que puede existir en una estrategia gubernamental que busca afectar el comportamiento inconsciente de los ciudadanos.

El artículo se compone de cuatro secciones, incluida esta introducción. La segunda sección sintetiza la discusión desde las neurociencias contemporáneas, que han sido la base para la corriente conocida como la economía conductual o del comportamiento (behavioral economics). En la tercera sección se discuten los principios de nudges y las corrientes críticas que han surgido contra ellos a la luz de la discusión del peligro de su supuesta falta de transparencia como instrumento de reforma. Esta crítica ha llevado a otras tres corrientes relacionadas con los nudges que se conocen como Think, Steery Punch! Por último, en la sección de

${ }^{13}$ Behavioural Insights Team, “EAST: Four Simple Ways to Apply Behavioural Insights”, Londres, 2014, en http://38r8om2xjhhl25mw24492dir.wpengine.netdna-cdn.com/wp-content/uploads/2015/07/BIT-Publication-EAST_FA_WEB.pdf; Mark Whitehead et al., Nudging All over the World, Reino Unido, Economic and Social Research Council, 2014.

14 Cass R. Sunstein, Simpler: The Future of Government, Nueva York, Simon \& Shuster, 2013.

${ }^{15}$ Jonathan Rowson, Transforming behavior Change: Beyond Nudge and Neuromania, Londres, RSA, 2011. 
conclusiones, se busca ordenar varias reflexiones sobre esta visión del gobierno conductual, apuntando a los límites y advertencias sobre las consecuencias sociales y políticas más importantes de su encumbramiento como posible nueva corriente de reforma y acción gubernamental.

\section{NeUrociencias, PSicología EVOLUTIVA y ECONOMÍA COMPORTAMENTAL: LAS BASES DEL IRRACIONALISMO PREDECIBLE}

La idea de que el ser humano escapa de las fuerzas biológicas, haciéndolo distinto de los demás animales, ha cambiado a lo largo de los siglos: desde la tradición judeo-cristiana, que asemeja al hombre a Dios y que lo pondera por encima de los animales, hasta la idea platónica de un ser humano cuyo comportamiento va guiado por dos caballos (la voluntad y las pasiones irracionales) conducidos por un actor capaz de dirigir su actuación (la razón). Sin embargo, la imagen o metáfora que tal vez ha perdurado más para explicar la idea de seres humanos que escapan de la biología debido a su esencia puramente social es la idea de la tabla rasa.

La expresión tabula rasa se ha empleado como punto de partida para explicar cómo funciona la mente y cómo adquirimos conocimiento. Básicamente, la idea de la tabla rasa se refiere a que la mente es un libro en blanco sobre el que a través de la experiencia y la educación se va escribiendo y moldeando, haciéndonos "lo que somos". ${ }^{16}$ Esta doctrina explica los pensamientos, las emociones y los comportamientos como un resultado de la socialización del individuo, es decir, por efecto de sus experiencias influidas exclusivamente por el entorno y la cultura. La idea de la tabla rasa va de la mano con el concepto del "buen salvaje" que Rousseau empleó para describir las culturas indígenas colonizadas, mismo que describe a una persona buena por naturaleza que nace libre de la maldad y el egoísmo. Bajo esta concepción, la sociedad es

${ }^{16}$ Steven Pinker, The Blank Slate: The Modern Denial of Human Nature, Nueva York, Penguin Books, 2002; Jonah Lehrer, op. cit. 
capaz de transformar al individuo por medio de la crianza y la construcción de instituciones. ${ }^{17}$

La tabla rasa muchas veces va relacionada con otra metáfora conocida como la del "espíritu dentro de la máquina" (ghost in the machine), atribuida al pensamiento de René Descartes. Él señaló que existe una diferencia entre mente y cuerpo, pues la primera es indivisible y es capaz de razonar y elegir libremente, mientras que la máquina o cuerpo está lleno de procesos mecánicos, rígidos y dependientes de las lógicas biológicas y naturales. Bajo esta idea, la mente es una causal sin causa, pues no funciona bajo las mismas reglas de la biología. Si la máquina actúa de manera poco racional, entonces es culpa de aquel espíritu que la dirige y no de carencias o falencias de la misma máquina. De esta manera, si el espíritu se equivoca no es por razones biológicas, sino más bien debido a su contexto, social y cultural, que lo ha inducido a actuar de manera errónea. ${ }^{18}$

Las doctrinas de la tabla rasa, el buen salvajey el espiritu dentro de la máquina enmarcan una concepción de la naturaleza humana en un campo de batalla entre la racionalidad (propiedad de la mente) y las emociones y deseos (propiedades del cuerpo animal), en el que la razón debe ser la vencedora para tomar mejores decisiones. Estas doctrinas, a veces de manera explícita y otras no tanto, han formado parte de supuestos y axiomas de muchas ciencias, sobre todo humanas y sociales. La separación tajante entre biología y sociedad, incluso se ha llegado a pensar como sustantiva para evitar errores garrafales como han sido las pseudoteorías de la eugenesia.

Sin embargo, estos supuestos de separación tajante entre biología y sociedad han sido atacados nuevamente con gran fuerza. Teorías como la sociobiología hablan ya de la necesidad de encontrar los vínculos, los lazos entre la biología y los estudios de la sociedad. ${ }^{19}$ Aunque esta línea de análisis (la sociobiología) es muy importante para el debate sobre los nudges, en este artículo nos

${ }^{17}$ Steven Pinker, op. cit., pp. 22-24.

${ }^{18}$ Steven Pinker, op. cit.; Jonah Lehrer, op. cit.

${ }^{19}$ Edgar Wilson, op. cit. 
concentraremos más bien en los argumentos que en este mismo sentido han surgido pero devenidos de las llamadas neurociencias, ${ }^{20}$ pues es desde aquí que teorías como los nudges han abrevado más recurrentemente para sostener sus argumentos.

Se puede comenzar diciendo que los últimos veinticinco años han sido testigos de una explosión de estudios en neurociencias que, gracias a nuevas técnicas no intrusivas como fMRI (functional Magnetic Resonance Imaging), han logrado observar y medir diversos procesos cerebrales de manera poco costosa (relativamente). Diversos de esos estudios han observado que no parece haber evidencia de que exista un proceso cerebral central que termine "controlando" o "decantando" la miríada impresionante de actividad neuronal que sucede todo el tiempo en el cerebro. Otra manera de decirlo es que no hay evidencia de un proceso cerebral centralizado que produzca lo que podríamos llamar una decisión. No hay un centro, o un homúnculo, sino que lo que se observa cerebralmente es un proceso sumamente intrincado de competencia entre diversos procesos neuronales, con el fin de producir una elección o una acción. En otras palabras, el cerebro es un complejo órgano con subsistemas que interaccionan y compiten entre sí para dar como resultado el proceso de decisión. ${ }^{21}$ No hay un centro de decisión racional, no hay manera de encontrarlo físicamente. Tampoco parece ser que la separación entre emociones y racionalidad sea tan clara, pues en realidad ambos procesos se interrelacionan y refuerzan a nivel neuronal. ${ }^{22}$

Aparentemente, las neurociencias han encontrado que la parte frontal del cerebro alberga complejos procesos relacionados con las emociones y no sólo procesos relacionados con el raciocinio. ${ }^{23}$ De esta manera las emociones se involucran en la toma de decisiones de manera automática, como una especie de base de datos,

${ }^{20}$ Particularmente la neuropsicología. Véase Nikolas Rose y Joelle Abi-Rached, op. cit.

${ }^{21}$ Como han argumentado: Daniel Kahneman, Pensar rápido, pensar despacio, México, Debate, 2012; David Eagleman, Incognito: The Secret Lives of the Brain, Nueva York, Pantheon, 2011; Jonah Lehrer, op. cit.; Steven Pinker, op. cit.

${ }^{22}$ Robert Wright, The Moral Animal, Nueva York, Vintage, 1994.

${ }^{23}$ Jonah Lehrer, op. cit., p. 17. 
donde el cerebro categoriza las emociones y sensaciones para luego ser usadas cada vez que se requiere decidir en alguna situación. Es decir, las emociones permiten decantar (por repulsión o por agrado, por ejemplo) para que, en efecto, una decisión sea tomada: de otra forma, el análisis "sin emociones" de las opciones lleva a la persona a analizar infinitas posibilidades y cálculos de costos y beneficios sin capacidad de decantarse, finalmente, por alguna de las opciones. De este modo, el proceso de decisión ocurre cuando diferentes partes del cerebro -en un juego de competencia y relación- "deciden" la opción "ganadora"; y en parte ese proceso es intervenido por pulsiones emocionales relativamente automáticas que presionan a una elección en tiempos concretos. ${ }^{24}$ No existe el famoso homúnculo, o ese pequeño hombrecillo, en el cerebro que concentra, jerárquicamente, en un mecanismo de proceso toda la información. En realidad, diferentes partes del cerebro compiten y se relacionan con el fin de "declarar" la "decisión" final que se hará consciente. ${ }^{25}$ Y entre estos procesos, las emociones son elementos relevantes.

Es de entenderse, en este sentido, una cuestión crítica adicional: todo este proceso se realiza sin que seamos conscientes de ello. Y es aquí donde las emociones juegan un papel fundamental. Incluso, famosos experimentos indican que este sistema inconsciente, y en cierto sentido automático, es capaz de realizar acciones suficientemente sofisticadas sin que el consciente domine. ${ }^{26}$ Por lo tanto, bajo esta óptica, razones y emociones son dos caras de la misma moneda. Las emociones pueden ser vistas como procesos neuronales de un órgano evolucionado como el cerebro. La razón, el consciente, es un elemento cerebral fundamental, pero no parece que sea el resultado particularmente central del proce-

${ }^{24}$ Paul Glimcher, Foundations of Neuroeconomic Analysis, Oxford, Oxford University Press, 2011.

25 Daniel Dennett, Intuition Pumps and other Tools of Thinking, Nueva York, Norton \&Co, 2013, p. 325.

${ }^{26}$ Los experimentos de George Gilles de la Tourette fueron famosos justamente por demostrar que los pacientes no podían evitar movimientos involuntarios constantes. El descubrimiento del llamado "Síndrome de Tourette" fue un parteaguas en el debate del libre albedrío, y de lo que concebimos como libertad al tomar una decisión aparentemente deliberada. Véase David Eagleman, op. cit. 
so: el cerebro maneja procesos inconscientes de alta velocidad (todos los procesos biológicos y fisiológicos que nos mantienen vivos, por ejemplo), donde emociones y pulsiones son elementos sustantivos y se intercalan con los procesos de cálculo y decisión de manera sistemática. Procesos conscientes e inconscientes están relacionados: algunos estudios han incluso propuesto aseveraciones atrevidas, como que es posible que una decisión racional haya sido en realidad "decidida" antes por procesos inconscientes. ${ }^{27}$

Las consecuencias de estos argumentos son enormes, si bien han sido cuestionados y el debate está vivo todavía. ${ }^{28}$ No vamos a entrar en este debate, importante e interesante, bien que sobrepasa el objetivo de este artículo. La cuestión para nuestro argumento es que las neurociencias han abierto una discusión que vincula profundamente a la sociedad y la biología: no hay tabla rasa, el cerebro es un órgano biológico que ha evolucionado de modo que es la razón de que decidamos y tengamos conciencia. Pero estas características humanas, decisión y conciencia, son tanto productos biológicos como sociales. No siempre podemos escapar de nuestra biología. Al final de cuentas nuestra biología, siendo animales que hemos logrado sobrevivir y perdurar bajo la lógica de la evolución, ha construido una serie de procesos de reacción que se juegan y se generan en la fisiología de cada una de las personas, como especie. ${ }^{29}$ El filósofo Dennett lo intenta explicar: no significa que estemos atrapados en los instintos y que la sociedad no importe; todo lo contrario: podemos moldear los instintos y podemos escapar de sus peores consecuencias, pero no negando que las fuerzas

${ }^{27}$ El estudio de Libet ha sido criticado y cuestionado desde sus bases a lo largo de los años, es necesario decir; véase Benjamin Libet, "Unconscious Cerebral Initiative and the Role of Conscious Will in Voluntary Action", Behavioral and Brain Sciences, vol. 8, 1985, pp. 529-566; Edward Vul et al., "Puzzlingly High Correlations in fMRI Studies of Emotion, Personality, and Social Cognition", Perspectives on Psychological Science, vol. 4, núm. 3, 2009, pp. 274-290; Klaus Fiedler, "Voodoo Correlations Are Everywhere: Not only on Neouroscience", Perspectives on Psychological Science, vol. 6, núm. 2, 2011, pp. 163-171.

${ }^{28}$ Raymond Tallis, Aping Mankind, Durham, Acumen, 2011; S. Satel y S. O. Lilienfeld, Brainwashed: The Seductive Appeal of Mindless Neuroscience, Basic Books, 2013.

${ }^{29}$ Read Montague, How We Make Decisions, Nueva York, A Plume Book, 2006. 
biológicas que nos afectan -desde nuestro más íntimo accionarsean elementos clave de las acciones humanas y de nuestra sociedad. ${ }^{30}$ En pocas palabras, cuando decidimos, se genera un producto neurológico, biológico, consciente, inconsciente, social y cultural. ${ }^{31}$ Todo al mismo tiempo, en una profunda interrelación.

Sin embargo, las consecuencias de esta interrelación no son inocuas. Si parte de que lo que llamamos razón es un producto también de emociones y de lógicas inconscientes, entonces, en efecto, no tenemos control (completo) ni manera racional (pura), de dirigir, diseñar y recomponer lo que hacemos, decimos y construimos individualmente. Y para el caso, entonces, socialmente tampoco. No siempre, al menos. Por tanto, intentar el control total racional de comportamientos estaría en este sentido, lógicamente, destinado al fracaso.

Es por ello lógico pensar que la mente humana cometa errores sistemáticamente, debido a los sesgos y atajos automáticos que, de manera inconsciente, se disparan como parte del proceso de pensamiento. Este ha sido argumento clave de Amos Tversky y Daniel Kanheman desde sus estudios iniciales en la década de 1970. ${ }^{32}$ Las personas, enfrentadas a diversas situaciones con incertidumbre o información determinada, reaccionan y toman decisiones según heurísticas muy posiblemente construidas bajo procesos evolutivos y sociales, las cuales son útiles en determinadas circunstancias, pero que en otras pueden llevar a decisiones equivocadas en el tiempo. Incluso se puede argumentar que se ha desarrollado en los seres humanos capacidades indispensables para mentirse a sí mismo, con el fin de soportar la realidad compleja de una manera menos angustiante y hasta más efectiva. ${ }^{33}$ En todo caso, las heurísticas estudiadas desde tiempos de Simon, ${ }^{34}$ y

${ }^{30}$ Daniel Dennett, op. cit.

${ }^{31}$ Daniel Bor, The Ravenous Brain, Nueva York, Basic Books, 2012.

32 Amos Tversky y Daniel Kahneman, "The Framing of Decision and the Psychology of Choice”, Sciences New Series, vol. 21, núm. 4881, 1981, pp. 453-458.

${ }^{33}$ Por paradójico que esto suene, véase David Smith, Why We Lie, Nueva York, St. Martin's Griffin, 2004.

${ }^{34}$ Herbert Simon, Administrative Behavior, Chicago, Chicago University Press, 1947. 
profundizadas por Gigerenzer, ${ }^{35}$ han adquirido un sesgo más mecánico y ordenado con Kanheman y Tversky. Estos autores, clave para los argumentos contemporáneos de los nudges, ${ }^{36}$ han propuesto, por ejemplo, que en ocasiones cuando las personas se enfrentan a situaciones de incertidumbre ocurre un fenómeno llamado aversión a la pérdida: un proceso mental que lleva a calcular desproporcionadamente el riesgo de perder sobre la oportunidad de ganar. ${ }^{37}$ Esto forma parte del sesgo de negatividad en el cual se asume que las personas ponderan con mayor importancia lo "malo" y que tomarán decisiones para evitar cualquier tipo de pérdidas. Este sesgo puede llevar a situaciones confusas para el cerebro, por ejemplo en las compras con tarjeta de crédito.

De igual manera, la mente inventa patrones como un mecanismo para resolver situaciones inciertas ante eventos aleatorios. Este atajo ha ayudado a la humanidad a aprender de sus errores y evitar cometerlos nuevamente en escenarios similares; sin embargo, la mente puede tomar decisiones basándose únicamente en sistemas imaginarios. Este sesgo es usado por el cerebro en situaciones con alto grado de aleatoriedad, como invertir en la bolsa de valores o incluso en las máquinas tragamonedas de los casinos, situaciones que se pueden volver adictivas ya que la mente busca adivinar una y otra vez las combinaciones de las figuras que arroja para obtener una recompensa. ${ }^{38}$

Desde la economía comportamental también se han estudiado ciertos sesgos y atajos de la mente. El sesgo de descontar el futuro requiere de un sistema de recompensas que el cerebro usa cuando se enfrenta a situaciones gratificantes; sin embargo, esto conduce a menoscabar la recompensa a largo plazo. Estas respuestas cerebrales están asociadas a ciertos comportamientos impulsivos, a evitar

${ }^{35}$ Gerd Gigerenzer, Gut Feelings: The Intelligence of the Unconscious, Nueva York, Penguin, 2007; y Gerd Gigerenzer, Reckoning with Risk: Learning to Live with Uncertainty, Nueva York, Penguin, 2002.

36 Tanto académica como políticamente, puede decirse; véase R. Jones, J. Pykett y M. Whitehead, Changing Behaviours: On the Rise of the Psychological State, Cheltenham, Edward Elgar, 2013.

${ }^{37}$ Lehrer, op. cit., p. 77.

${ }^{38}$ Ibid., pp. 65-67. 
que la gente ahorre con más atingencia para su vejez, e inclusive se ha estudiado en personas que terminan cayendo en adicciones. ${ }^{39}$ Otros ejemplos clásicos tienen que ver con la forma en que los seres humanos están sesgados para evadir el riesgo, crear velozmente en la mente patrones ante eventos diversos, calcular en pocos segundos afinidades y fobias en sus relaciones con otros, adaptar sus preferencias a las circunstancias, entre otros. La cuestión clave es que esas mismas estrategias pueden ser un obstáculo para tomar decisiones racionales: buscando, por ejemplo, decidir una cantidad de ahorro mensual, una persona puede ser demasiado optimista respecto de supuestas bajas probabilidades de tener cáncer en el futuro. El optimismo necesario para tener voluntad para seguir viviendo puede ser contraproducente para establecer una visión más realista de la necesidad de un ahorro mayor cada mes. Prejuiciar a las personas es una manera rápida de entablar (o no) vínculos sociales por medio de la empatía; pero ese mismo mecanismo puede también animar sentimientos y lógicas sociales como el racismo $u$ otros mecanismos de pertenencia al grupo que eviten la cooperación a mayor escala. Adaptar las preferencias a las circunstancias puede ser elemental para mantener cierta felicidad y cordura en un mundo incierto (no se puede obtener todo lo que uno quiere); sin embargo, se puede caer en el fomento de cálculos equivocados con consecuencias negativas. Éste es el caso del proceso mental mejor conocido como razonamiento iluso o wishful thinking; por ejemplo: fumar causa cáncer, pero como asumo que soy especial es probable que a mí no me dé esa enfermedad. Estos errores o límites de la racionalidad ${ }^{40}$ están, por tanto, íntimamente incrustados en nuestras construcciones sociales a partir de eventos evolutivos de largo plazo.

En un extremo de esta perspectiva, se podría ubicar la situación conocida como "neuroeconomía", donde se está estudiando cómo la empatía y ciertos comportamientos prosociales pueden ser decisiones que se tomen con ayuda de procesos biológico-neuronales,

${ }^{39}$ David Eagleman, op. cit.

${ }^{40}$ Jon Elster, Salomonic Judgments: Studies in the Limitations of Rationality, Cambridge, Cambridge University Press, 1989. 
como la liberación de oxitocina, un neurotransmisor relacionado con el placer o la empatía. La oxitocina, al parecer, afecta comportamientos sociales de maneras muy profundas. ${ }^{41}$

Como puede observarse, la integración de ciencias sociales -la economía entre ellas-, disciplinas como la sociobiología y ciertos estudios neurocientíficos contemporáneos plantean, entonces, una nueva base de argumentación respecto de las personas y las sociedades. El punto principal parece ser el que poderosas fuerzas fisiológicas y neurológicas afectan el comportamiento de las personas y de las sociedades. Dichas fuerzas son en su mayor parte inconscientes -fuera del control de los seres humanos-, pero no por serlo han dejado de ser integradas y "resueltas" mediante diferentes vías por los seres humanos y sus sociedades, todo lo contrario. Las personas y las sociedades han creado atajos, fórmulas heurísticas, reacciones y hábitos, que han logrado con gran éxito -a lo largo de los tiempos- permitir a los seres humanos sobrevivir y hasta lograr cierto control sobre su entorno. La clave está en comprender cómo esas respuestas heurísticas son un arma de doble filo: muchas veces funcionan pero otras tienen consecuencias no deseadas. ¿Se pueden modificar esas respuestas heurísticas para evitar muchas de consecuencias no deseadas, siendo que como respuestas son muchas veces no conscientes?

\section{Nudges, Think, Steer, Punch!: la batalla por la legitimación} DE LA INTERVENCIÓN GUBERNAMENTAL SOBRE EL COMPORTAMIENTO

De una u otra manera, el gobierno siempre ha utilizado herramientas para afectar o modificar el comportamiento de las personas: a través de impuestos, legislaciones, regulaciones, señalizaciones o amenazas y castigos. Muchos de estos instrumentos en la práctica asumen que las personas son, en cierto sentido, racionales, y que usando la razón el convencimiento directo, ayudando a la persona

41 Véase Paul J. Zak (ed.), Moral Markets, Princeton, Princeton University Press, 2008; Paul J. Zak, "The Physiology of Moral Sentiments", Journal of Economic Behavior Ẽ Organization, vol. 77, núm. 1, 2011, pp. 53-65. 
a que calcule las consecuencias de sus actos, se alcanzará un objetivo complejo: que las personas cambien estructuralmente su comportamiento. Muchos de estos instrumentos confían tanto en la racionalidad de las personas que se asume que cuando no se logra el cambio de comportamiento deseado es porque dichas personas que no cambiaron son, francamente, irracionales (y deberán sufrir las consecuencias, que pueden ir desde la pérdida de beneficios hasta la libertad).

La agenda del gobierno conductual propone una visión distinta de la naturaleza humana y, por lo tanto, de muchos de los instrumentos del gobierno. Establece como base un mayor grado de comprensión de la condición humana, tomando en cuenta los elementos irracionales del comportamiento, para el diseño de políticas. Estas nuevas estrategias toman en cuenta, por un lado, los límites de la capacidad cognitiva de la mente y, por otro, la forma en la que éstos condicionan la toma de decisiones; e incluso cómo estos condicionamientos pueden ser sociales a la vez: la reputación de una persona al final de cuentas es también un producto mental y social tanto racional (reputación por actos concretos) como irracional. ${ }^{42}$

Para los defensores de la visión conductual, la influencia inteligente sobre el comportamiento de las personas es central para las políticas públicas. Esta nueva forma de diseño de políticas se basa en estudios empíricos que muestran cómo se comportan las personas bajo diferentes circunstancias, a partir de sus reacciones inconscientes y no a cómo responden conscientemente ante incentivos económicos. ${ }^{43} \mathrm{Al}$ intentar estudiar la lógica inconsciente de la decisión y la acción de las personas, la clave es comprender que la afectación al comportamiento no puede lograrse exclusivamente con instrumentos dirigidos a la parte consciente o racional. Comprender a los seres humanos, a lo que hacen y deciden, implica ser capaz de vislumbrar cómo sus decisiones y acciones son un

42 Reputación por cualidades físicas o morales subjetivamente atribuidas a las personas véase John Whitfield, People Will Talk, Nueva Jersey, John Wiley \& Sons, 2012.

${ }^{43}$ David Halpern et al., Personal Responsibility and Changing Behavior: The State of Knowledge and its Implications for Public Policy, Londres, Strategy Unit, 2004, p. 4. 
claroscuro de racionalidad e irracionalidad. ${ }^{44}$ Se hace necesario encontrar y diseñar nuevos instrumentos que sean capaces de impactar ese lado irracional con el fin de impulsar a los individuos a tomar mejores decisiones, así no sean éstas enteramente conscientes.

De esta manera, una creciente serie de estrategias e instrumentos de este cuño han aparecido en el espectro; entre los más famosos, los nudges. Desde su nacimiento en discusiones académicas -hasta su implementación tanto en las oficinas de Información y Asuntos Regulatorios (Estados Unidos) como en el Equipo de Ideas Comportamentales (Reino Unido)-, los nudges están cambiando el diseño de varias políticas públicas en diversos ámbitos. Es importante recordar que la lógica de los nudges ha sido defendida como un paternalismo libertario por dos de sus autores: ${ }^{45}$ una intervención que deja a las personas la libertad de su decisión, pero siendo una decisión afectada por el estado para permitir al individuo sobrepasar sus limitaciones inconscientes. Es justamente esta idea de intervención sobre el inconsciente por lo que la estrategia de los nudges está siendo criticada, en la búsqueda de otras formas más éticas o más participativas de intervención. Entre estas estrategias encontramos alternativas como Think, o pensar, y Steer, o dirigir. Un cuarto grupo de estudiosos ha contrastado las tres corrientes anteriores a partir de la teoría social de Foucault. Se denomina a esta visión con el lúdico concepto de Punch! Revisaremos primero los principios mínimos de los nudges y, posteriormente, estas otras estrategias que podemos denominar de resistencia al "paternalismo libertario" (véase un resumen en el cuadro 1).

\section{Nudges}

El mayor cambio para el diseño de políticas es que los nudges apuestan a modificar el contexto en el momento en que las personas toman las decisiones más que su forma de pensar. Esta estrategia comportamental se sirve de la denominada arquitectura de

${ }^{44}$ Robert Trivers, The Folly of Fools, Nueva York, Basic Books, 2011.

${ }^{45}$ Richard Thaler y Cass Sunstein, op. cit. 
decisiones para que los individuos opten por las alternativas que sean más favorables para su bienestar. Por lo tanto, los arquitectos de decisiones son aquellos que tienen la responsabilidad de organizar el contexto en el que las personas eligen. ${ }^{46}$ Esta configuración del ambiente en el que las personas pueden decidir de forma libre busca que la atención de los individuos se oriente hacia cierta dirección y de esta manera lograr que tomen mejores decisiones que se reflejen en su salud y bienestar en general. Aquellos que diseñan las políticas deben tener presentes las limitaciones cognitivas de las personas, las heurísticas y atajos en la mente de las personas para poder diseñar los nudges adecuados.

Un nudge es cualquier estrategia usada por los arquitectos de decisiones para modificar el comportamiento de las personas de manera predecible, no agresiva, sin prohibir ninguna de las opciones ni cambiando de manera significativa sus incentivos económicos. ${ }^{47}$ Para que un nudge pueda serlo debe preservar la capacidad de elegir del individuo, por lo tanto, los impuestos, subsidios o sanciones no pueden ser considerados nudges.

Esta estrategia, que se sostiene en buena parte de los argumentos de Amos Tversky y Daniel Kanheman, reconoce dos sistemas en la mente humana: el sistema reflexivo y el sistema automático. El primero es aquel que utilizamos para llevar a cabo una tarea de manera consciente, que requiere de mayor análisis y esfuerzo. El consciente es un recurso escaso que el cerebro "conecta" sólo cuando es necesario, ante su lentitud y su parsimonia. En cambio, el sistema automático es aquel que lleva a cabo tareas de manera inconsciente como los sesgos y atajos descritos anteriormente; es sumamente veloz, efectivo, aunque la persona difícilmente tiene control de este sistema al ser sustantivamente inconsciente. En este nivel, además, se involucran elementos como los reflejos y las emociones. Desde el control de las funciones vitales hasta otros actos más sociales como intuir las intenciones de otras personas, forman parte de este sistema automático. ${ }^{48}$ Un arquitecto de decisión debe

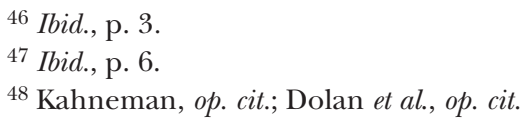




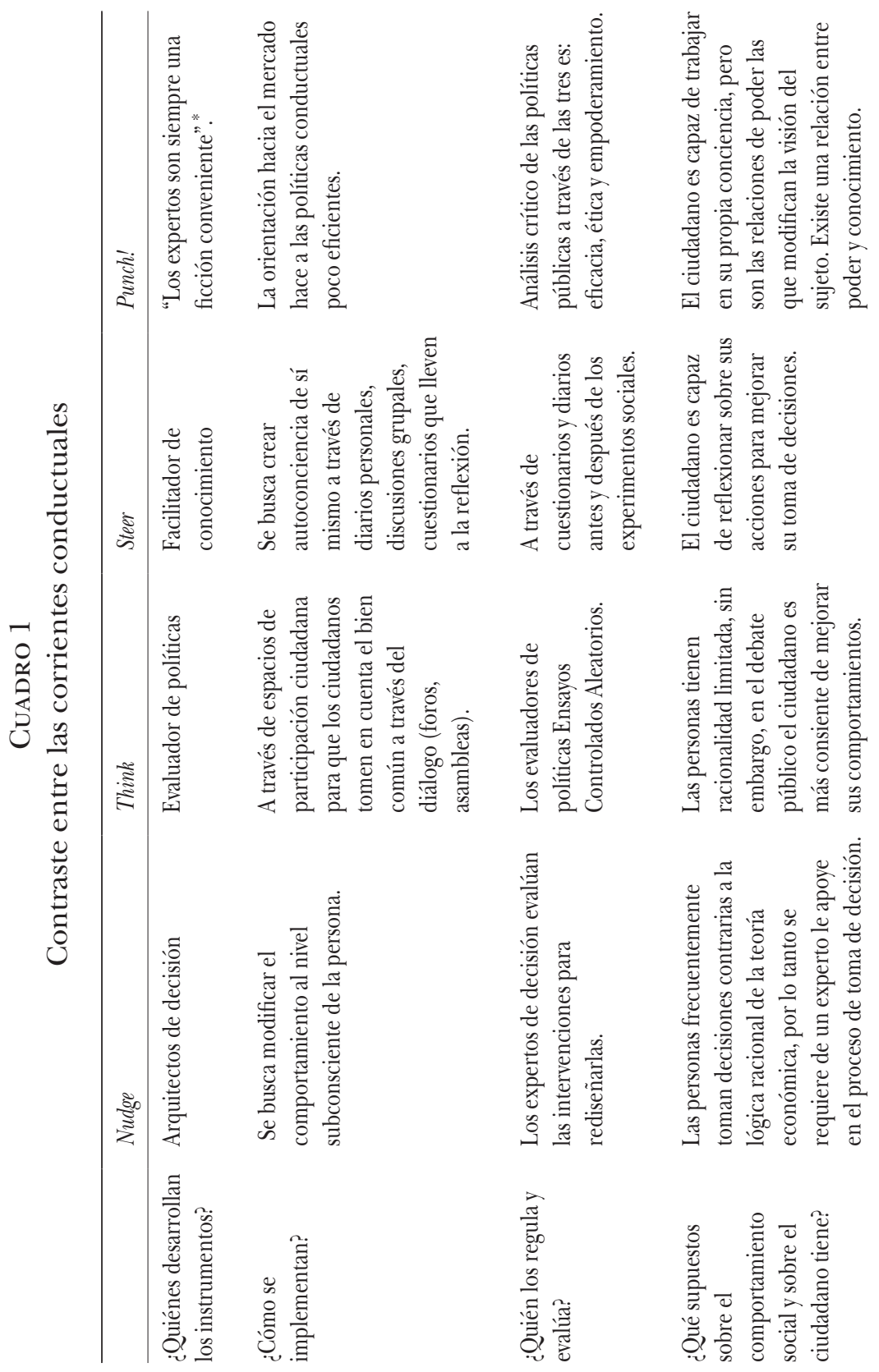



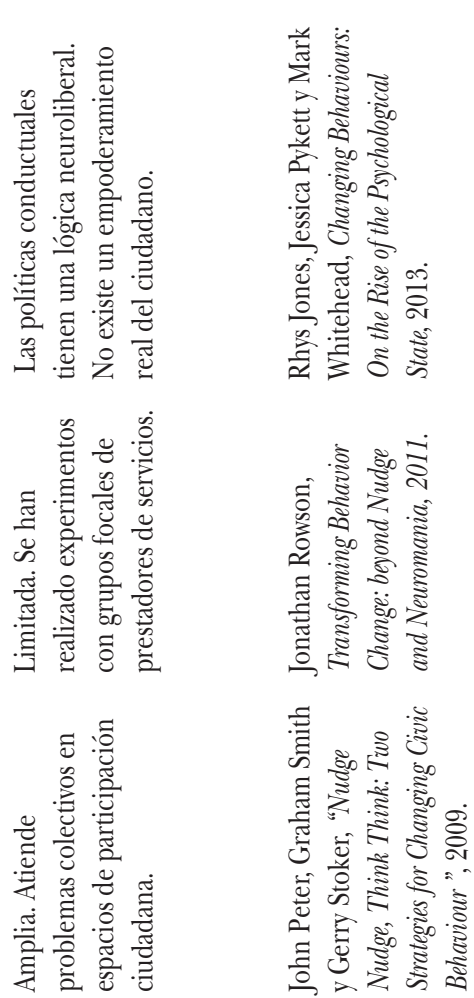

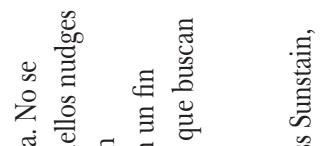

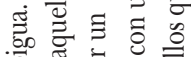

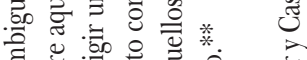

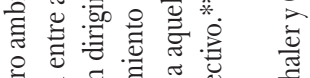

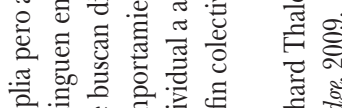

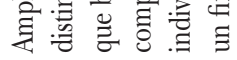

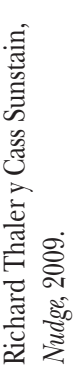

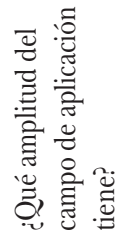

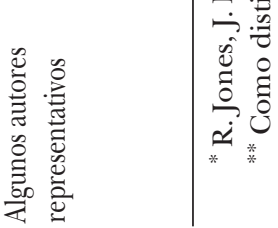


ser capaz de conocer cómo funcionan estos dos sistemas para el diseño de los nudges, la forma tradicional de hacer políticas apostaba a cambiar el comportamiento de las personas desde el sistema reflexivo. Los nudges, en cambio, se enfocan en cambiar el contexto en el que el sistema automático actúa, tomando en cuenta los atajos y sesgos que de manera inconsciente tiene la mente humana sobre las acciones.

Los arquitectos de decisiones utilizan seis principios para desarrollar diferentes nudges: ${ }^{49}$

1) Incentivos. La oferta y demanda del libre mercado usualmente le presenta un complejo sistema de incentivos a las personas. Desde el análisis conductual, las personas pueden subestimar o sobreestimar los incentivos que el mercado les presenta tomando malas decisiones, así que los arquitectos de decisiones deben ser capaces de dirigir la atención de los individuos hacia los incentivos correctos.

2) Mapas mentales. Las personas suelen tomar decisiones frente a escenarios adversos. Un sistema de arquitectura de decisión sería capaz de ayudar a las personas a traslapar las opciones a unidades de medida, mapas o patrones que sean más comprensibles para ellas. Las personas ahorrarían más para su pensión si se les ayuda a imaginarse -de manera más concreta- cómo serán físicamente (y qué dolencias físicas podrían probablemente tener) cuando tengan 70 años.

3) Defaults. Son posiciones iniciales en las cuales no es necesario que las personas realicen una acción para llegar a ésta. Apuestan por utilizar el fuerte poder de la inercia sobre el comportamiento a favor de una decisión benéfica; aquellos que no estén conformes con esta posición inicial tienen la libertad de cambiarla. En este principio es necesario decidir si se cambia o se mantiene esta posición inicial; nadie se exenta de tomar una decisión. Por ejemplo, que todos los trabajadores al entrar a trabajar tengan por defecto el mismo sistema de pensión y aquel que lo prefiera puede cambiarlo; o hacer de la donación de órganos el default; y si la persona no quiere ser donadora, debe solicitar ser sacada del sistema (al revés de como hoy día en muchos países se asume debe ser esta decisión).

49 Thaler y Sunstein, op. cit. 
4) Retroalimentación. Consiste en proveer a las personas de información sobre las implicaciones de sus decisiones. Estos mecanismos proporcionan información al individuo cuando está actuando de manera correcta o incorrecta, o cuándo está a punto de tomar una mala decisión. En San Marcos, California, se implementó un sistema de retroalimentación visual para fomentar el uso de energía de manera responsable. En él, los hogares reciben dibujos de caras felices o tristes dependiendo de su nivel de consumo.

5) Expectativa de error. El sistema de nudges debe prever los errores que las personas podrían cometer. Tanto el metro de París como los estacionamientos públicos en Chicago han implementado sistemas en los que no importa de qué manera se inserte el boleto o la tarjeta de crédito, ésta siempre será correcta.

6) Estructura de decisiones complejas. Conforme las opciones se vuelven más numerosas y complejas, las personas requieren de una estructura que les ayude a ordenar sus preferencias y que sirva como un filtro de sus necesidades. Los buscadores en Internet son un ejemplo, en los que se sugieren páginas de acuerdo a búsquedas anteriores.

El paternalismo libertario es la corriente que enmarca a los nudges; algunas críticas han surgido por ser considerado un oxímoron, ${ }^{50}$ pero para Thaler y Sunstein es claro que el gobierno debe intervenir cuando el ciudadano no es capaz de llevar a cabo una elección para su propio beneficio. Siguiendo esta lógica, la intervención se justifica una vez que las opciones pueden ser fáciles de evitar ya que de esta manera no se restringe la libertad individual a la vez los costos gubernamentales se reducen considerablemente. ${ }^{51}$

\section{El caso británico}

Cuando David Cameron comenzó sus funciones como primer ministro en 2010, una de sus primeras acciones fue la creación de lo

50 Como ha señalado Gregory Mitchell, "Libertarian Paternalism Is an Oxymoron”, Northwestern University Law Review, vol. 99, núm. 3, 2005.

${ }^{51}$ Ibid., p. 252. 
que los británicos conocen hoy como la "Nudge Unit". El Equipo de Ideas Conductuales (BIT, por sus siglas en inglés) comenzó como una parte de la oficina del gabinete con el fin de institucionalizar las herramientas de comportamiento en el diseño de políticas. Fue la primera institución gubernamental dedicada exclusivamente a la aplicación de las ciencias del comportamiento en el diseño de políticas aunque al día de hoy trabaja independiente del gabinete. ${ }^{52}$

El Biт sigue una metodología de cuatro ejes: 1) definir un resultado, 2) entender el contexto, 3) construir la intervención y 4) probar, aprender, adaptar. A partir de este marco, el gobierno tiene que definir cuál es el comportamiento que quiere influir; entender el contexto desde la perspectiva de las personas; y propiciar la construcción de una intervención medible usando ensayos controlados aleatorios (ECA) . Tomado de la investigación médica, los ECA ayudan en el proceso de evaluación al mismo tiempo que dan suficientes resultados para el rediseño de las intervenciones. Muestra cómo la gente se comporta bajo diferentes circunstancias durante la ejecución de cada intervención y cómo su alcance está aumentando en más áreas de las políticas públicas. Su principal objetivo es apreciar la efectividad, contrastando dos o más intervenciones y logrando un resultado medible..$^{53}$ Aunque los resultados de estas evaluaciones son de acceso público, para algunos nudges es necesario que el ciudadano no tenga conocimiento del (re) diseño de la intervención. Esto ha traído diversas críticas porque eso vuelve ambigua la definición del nudge ${ }^{54}$ y es problemático cuando se analiza la transparencia y "libertad de decisión" de las intervenciones.

${ }^{52}$ Behavioural Insights Team, "EAST: Four simple ways...".

${ }^{53}$ Laura Haynes et al., "Test, Learn, Adapt: Developing Public Policy with Randomised Controlled Trials”, Londres, Behavioural Insights Team, 2012, p. 8, en: https://www.gov.uk/government/publications/test-learn-adapt-developing-publicpolicy-with-randomised-controlled-trials

${ }^{54}$ Jeroen van der Heijden y Mark Kosters, "From Mechanism to Virtue: Evaluating Nudge-Theory", RegNet Research Papers, núm. 80, Regulatory Institution Network, 2015. 
Dentro de las políticas del віт podemos encontrar las siguientes: ${ }^{55}$

- Sistema de pensiones de autoinscripción. En 2012 se implementó este sistema en empresas de gran escala. En los primeros seis meses aumentaron las tasas de participación entre 61 y $83 \%$. El objetivo principal fue atacar el poder de la inercia; los trabajadores inscritos automáticamente pueden dejar el sistema de pensiones en cualquier momento.

- Registro de donadores de órganos. Una de las principales razones de su éxito es que las personas pueden inscribirse como donantes al renovar su licencia de conducir; también un simple cambio en el mensaje que las personas recibieron ayudó a tener 100000 donantes adicionales registrados en 2013: "Si usted necesitara un trasplante de órganos, ¿aceptaría usted uno? Si es así, por favor, ayude a los demás".

- Recordatorios con la imagen de los vehículos que no han pagado sus impuestos y que al mismo tiempo muestra que otras personas pagan a tiempo. Esto aumentó las tasas de pagos usando normas sociales e incentivos individuales; ayudó a aumentar los pagos de impuestos entre 40 y 49\% de 2011 a 2012.

Sin embargo, no todas las intervenciones han sido exitosas. Algunas políticas que comparten los comportamientos de otros ciudadanos tienden a ser menos efectivas (al proporcionar dicha información las políticas pueden considerarse las más transparentes). Por ejemplo, cuando algunas personas recibieron una cara sonriente al realizar una menor emisión de energía que el promedio de sus vecinos, la política tuvo el efecto contrario al deseado, pues aumentaron el consumo de energía en el siguiente periodo al sentirse ciudadanos "demasiado buenos". ${ }^{56}$ Otras críticas consisten en que las intervenciones que se etiquetan como nudges podrían no serlo en absoluto. Digamos que el gobierno busca disminuir las tasas de embarazos en adolescentes y pone en marcha un programa de mentores juveniles con el fin de hacer reflexionar

\footnotetext{
${ }^{55}$ Nos basamos en informes de Behavioural Insights Team, "EAST: Four Simple Ways...".

${ }^{56} \mathrm{~J}$. Van der Heijden y M. Kosters, op. cit.
} 
a los jóvenes sobre la responsabilidad de cuidar a niños pequeños. ${ }^{57}$ En estricto sentido la política no podría catalogarse como nudge, pues más que modificar el contexto de la toma de decisiones de los jóvenes busca llevarles a un proceso de reflexión.

Gran Bretaña fue el primer gobierno que invirtió en la agenda del comportamiento de una manera formal; fue el país pionero en la ola de los nugdes y fue seguido por muchos otros. Hoy en día, Estados Unidos, Francia y Dinamarca también cuentan con sus propias oficinas de comportamiento: la Oficina de Información y Asuntos Regulatorios, el Centro de Análisis Estratégico y iNudgeYou, respectivamente. ${ }^{58}$

\section{Think}

Think es una estrategia promovida por un grupo de politólogos de las universidades de Manchester y Southampton, quienes desarrollaron una alternativa a los nudges basándose en la democracia deliberativa, en la que los ciudadanos toman decisiones informadas partiendo del diálogo público. ${ }^{59}$

Mientras que los nudges apuestan por modificar el contexto de la toma de decisiones en el momento, Think busca que las instancias públicas sean capaces de crear un marco institucional lo suficientemente fuerte para que los individuos puedan superar su racionalidad limitada, y así se llegue a soluciones colectivas. Las instituciones son las que, por medio de foros públicos, logran hacer que los ciudadanos interioricen comportamientos cívicos gracias al diálogo libre y público con otras personas. Los defensores de Think intentan construir un comportamiento cívico con el que las personas logren ser capaces de tomar mejores decisiones, y con ello aumentar la participación ciudadana en temas como el medio ambiente, la donación de órganos, el voluntariado y las votaciones.

${ }^{57}$ Adam Oliver, "Nudging, Shoving and Budging: Economic-Informed Policy”, Public Administration, vol. 3, núm. 3, 2015, pp. 700-714.

${ }^{58}$ Mark Whitehead et al., Nudging All over the World, Reino Unido, Economic and Social Research Council, 2014, p. 25.

${ }^{59}$ R. Jones, J. Pykett y M. Whitehead, op. cit., p. 163. 
Think busca el cambio en el comportamiento a través de los procesos conscientes del individuo y pone sus esfuerzos en la razón y la reflexión de las personas. ${ }^{60}$ Esta corriente deliberativa ha servido de punto de partida para diseñadores de políticas logrando empoderar al ciudadano de formas novedosas, como el presupuesto participativo, asambleas públicas y foros por Internet, incluyendo especialmente a grupos vulnerables en el debate de los asuntos públicos. ${ }^{61}$

La deliberación llevada a cabo de manera libre e igualitaria tiene efectos cognitivos para el ciudadano, pues aumenta su entendimiento sobre las consecuencias de sus actos; hacerlo de manera pública restringe el interés individual y se toma en cuenta el bien común. En otras palabras, en el debate público tendemos a ser más conscientes de nuestros deberes como miembros de una comunidad, con que motiva a tener mejores comportamientos. ${ }^{62}$

Mientras que en la estrategia de los nudges el cambio es individual, en Think se apuesta por transformar las preferencias de manera grupal, atendiendo a la raíz del problema. En este último debe existir un mayor compromiso por parte del individuo, y a diferencia de nudge Think implica mayores costos en suministrar la información y llevarla al debate público. Para que funcione, el diseño de políticas se debe realizar bajo marcos de colaboración con los ciudadanos y su legitimidad reside en el intercambio libre de opiniones y el diálogo respetuoso e igualitario. ${ }^{63}$

Un ejemplo de la implementación de esta estrategia es un ejercicio llevado a cabo por la Asamblea de Ciudadanos de British Columbia; el objetivo era emitir una recomendación sobre la reforma electoral que se planeaba para la provincia. Los participantes se eligieron de manera aleatoria, cuidando las representaciones por edad, género y región geográfica. El ejercicio constó de tres fases:

${ }^{60}$ Rowson, op. cit.

${ }^{61}$ Peter John, G. Smith y G. Stoker, "Nudge Nudge, Think Think: Two Strategies for Changing Civic Behaviour”, The Political Quarterly, vol. 80, núm. 3, julioseptiembre de 2009, p. 365

${ }^{62}$ Loc. cit.

${ }^{63}$ Peter John et al., Nudge, Nudge, Think Think. Experimenting with the Ways to Change Civic Behavior, Londres, Bloomsbury, 2011. 
la educativa, la consultiva y la deliberativa. En la primera, los participantes estudiaron los diferentes sistemas electorales así como su impacto; en la segunda, consultaron a los partidos políticos interesados; y, por último, en la fase deliberativa se llevó a cabo el consenso sobre las recomendaciones que se emitirían. Posteriormente, los resultados se iban a someter a referéndum para la ratificación pública del proceso. ${ }^{64} \mathrm{El}$ éxito del ejercicio llevó a cuestionar fuertemente las políticas que apuntan al inconsciente tipo nudge.

Los seguidores de esta estrategia apuestan a cambiar comportamientos que a largo plazo resultarán más benéficos para la sociedad al no existir opacidad en el proceso de implementación.

\section{Steer}

La dirección del comportamiento que busca Steer refuta la dicotomía entre el sistema reflexivo y el automático defendido por las estrategias estilo nudge. Este modelo holístico considera que los procesos reflexivos y automáticos influyen y se refuerzan uno al otro; por lo tanto, no es posible concebirlos de manera separada. ${ }^{65}$ Uno de los principales argumentos de Steer es que existe una gran diferencia entre los problemas técnicos y los retos de adaptación. Los problemas técnicos son fáciles de identificar y tienen una solución rápida que un experto desarrolla. Los retos de adaptación, en cambio, deben ser resueltos por aquellos que tienen el problema, y requieren de soluciones analíticas seguidas de un cambio en la actitud más que en el comportamiento de los individuos. Por ejemplo, una pastilla para adelgazar es una intervención técnica, mientras que cambiar de hábitos alimenticios y hacer ejercicio es un reto de adaptación. ${ }^{66}$ Los seguidores de esta estrategia, la mayoría miembros de la Real Sociedad para el fomento de las Artes, Manufactura y Comercio (RSA) en Inglaterra, consideran que gran parte de los problemas que enfrenta la sociedad en el

\footnotetext{
${ }^{64}$ Peter John, G. Smith y G. Stoker, op. cit.

${ }^{65}$ Rowson, op. cit.

${ }^{66}$ Ibid., p. 17.
} 
siglo xxI -como el cambio climático, inestabilidad financiera o los cambios demográficos-, tienen una naturaleza adaptable; es decir, se requiere que los individuos cambien ciertas actitudes y valores para solucionarlos. ${ }^{67}$ Bajo esta óptica, se busca crear autoconciencia en el ciudadano y sus acciones, utilizando el término reflexividad para referirse al proceso cognitivo de tener conciencia del mundo en el que se vive para poder cambiar una situación a favor de sí mismo.

A diferencia de Think y nudge, Steer busca una mayor introspección y utiliza explicaciones biológicas de las neurociencias para comprender los límites de la acción humana. Bajo la lógica de Steer, la racionalidad es limitada, conque se deben crear estrategias para racionalizar el comportamiento del ser humano y así lograr el dominio sobre sí mismo. Para Steer no existe un experto ni arquitecto de decisiones; más bien la idea es que con la ayuda de un facilitador de conocimiento es el ciudadano neurológicamente reflexivo ${ }^{68}$ quien se convierte en el experto de su propio cerebro y su comportamiento.

La RSA ha realizado investigaciones cualitativas donde se implementa la estrategia de Steer sobre grupos de policías, taxistas y ciudadanos en los que se busca que mejoren su relación con la sociedad, ahorren combustible o lleven a cabo hábitos saludables y ecológicamente amigables. Una de las investigaciones consistió en entregar una serie de reglas a un grupo focal para mejorar las decisiones que toman en el día a día; estas reglas iban desde ser conscientes de sus corazonadas hasta la reflexión en decisiones complejas. Las personas debían participar en discusiones grupales, responder cuestionarios y llevar un diario durante dos semanas en el que reportaban en qué medida las reglas les ayudaban a tomar mejores decisiones. Los reportes señalaron que los participantes aprendieron los consejos para tomar decisiones inmediatas

${ }^{67}$ Loc. cit.

${ }^{68}$ El término se refiere al proceso en el que se dota al ciudadano con información completa acerca de los procesos neurológicos y psicológicos, para que de esta manera tomen mejores decisiones y tengan mayor control sobre sí mismos, lo que lleve a comportamientos más racionales véase Jones, Pykett y Whitehead, $o p$. cit., pp. 179-180. 
y, en el largo plazo, a controlar sus instintos y mostrar una gran apertura a modificar sus hábitos por otros más saludables. ${ }^{69}$ No obstante, la filosofía detrás de Steer va más allá. La RSA fomenta la consolidación de una "Ilustración del siglo xxi" en la que el desarrollo humano depende de un mayor conocimiento científico de la naturaleza humana. Este conocimiento es lo que dará forma al comportamiento. ${ }^{70}$ En los seguidores de Steer existe la preocupación de encontrar las condiciones socialmente democráticas que logren el desarrollo de ciudadanos más capaces y con mejores comportamientos, sin dejar de lado la idea de la autonomía. ${ }^{71}$ Steer de alguna manera parte de los argumentos del sociólogo Giddens, sobre una condición humana dentro de una sociedad moderna y global, con tradiciones colapsadas y que vive la desintegración de concepciones locales. ${ }^{72}$ Por lo tanto, esos agentes que toman decisiones autónomas cobijadas por la modernidad tardía deben ser dirigidos a tener mejores comportamientos a la luz de la razón y de la ciencia. Pero visto entonces como un proceso social, no individual: un proceso social diverso, conflictivo, reflexivo. ${ }^{73}$

\section{Punch!}

Para esta corriente es importante contrastar las escuelas que construyeron la agenda conductual en estos últimos años, pues han transformado el objeto, sujeto y espacios de estudio del gobierno. ${ }^{74}$ Punch! analiza, desde los argumentos de Michel Foucault, la forma en que las estrategias conductuales abordan el poder, el conocimiento y el sujeto de estudio más que proponer diseños de política. Utilizan tres acercamientos a su discusión: la identificación de las relaciones de poder en la agenda política -inherentes a un cambio de comportamiento-; la forma en la que se entiende

${ }^{69}$ Ibid., p. 177.

${ }^{70}$ Rowson, op. cit:; Jones, Pykett y Whitehead, op. cit.

${ }^{71}$ Jones, Pykett y Whitehead, op. cit., p. 179.

${ }^{72}$ Loc. cit.

${ }^{73}$ Mols et al., op. cit, pp. 81-98.

${ }^{74}$ Jones, Pykett y Whitehead, op. cit. 
el sujeto a partir de una reconfiguración de los conceptos de naturaleza humana y ciudadano ideal; y las formas neuroliberales de gobierno que surgen a partir del reconocimiento de las nuevas disciplinas de estudio. ${ }^{75}$

Para ellos el "neuroliberalismo" ha surgido como una respuesta del neoliberalismo para modificar comportamientos que no son acordes a la lógica del mercado aunque a primera vista las corrientes conductuales busquen contrarrestar los efectos de las políticas neoliberales, modificando comportamientos sociales y de impacto ambiental, por ejemplo.

Los sujetos son ciudadanos que participan en la configuración de ciertas acciones para conseguir fines concretos -en el Estado moderno de Foucault, esto sería la salud, el bienestar y la riqueza $^{76}$-; y a través de ellas se llevan a cabo las relaciones de poder. En estas relaciones existe una estrecha relación entre poder y conocimiento. Este conocimiento se traduce en nuevas técnicas para el diseño de políticas, que se traslapan a la esfera política en la medida en la que son más abiertas o cerradas para el público; la forma en la que conciben la libertad para decidir; el objetivo neurológico o motivacional al que van dirigido, ya sea consciente e inconsciente, racional o emocional; así como la orientación económica, la cual busca que los individuos estén más preparados para decidir ante el mercado. ${ }^{77}$

Punch! relaciona esta preocupación del Estado sobre las decisiones que toman los individuos, con la idea del poder pastoral. Esta forma de poder reproduce las estructuras institucionales de la tradición cristiana, y es un poder que "no se puede ejercer sin conocer el interior de las mentes de las personas, sin explorar sus almas, sin que revelen sus más íntimos secretos. Esto implica un conocimiento de la conciencia y la habilidad para dirigirla". ${ }^{78} \mathrm{El}$ deseo de la salvación del ser humano de su propia irracionalidad; el surgimiento de actores mesiánicos, llámense evaluadores de políticas,

75 Ibid., p. 182.

76 Ibid., p. 183.

77 Ibid., p. 185.

${ }^{78}$ Foucault, 1982 citado en Jones, Pykett y Whitehead, op. cit., p. 186, traducción propia. 
investigadores o arquitectos de decisiones, y la necesidad de las estrategias conductuales por entrar en la conciencia de los ciudadanos son algunos de los argumentos que dan los seguidores de Punch! para cuestionarlo.

Por otra parte, Punch! identifica como una de las consecuencias del cambio conductual a la división del sujeto de otros; ya que se divide a los ciudadanos en aquellos capaces de tomar decisiones racionales y aquellos que no lo son, con acciones reflexivas o reacciones automáticas, que implementan soluciones técnicas o tienen retos de adaptación. Por ejemplo, para Punch! el modelo automático-reflexivo desarrolla un patrón en el que se etiqueta a las personas, ya sea como sofisticados individuos racionales o como personas demasiado incompetentes para cambiar su propio comportamiento. Considera que si se comprende a las personas como si fueran émulos de Homero Simpson, las personas se irán comprendiendo y definiendo en efecto como él. ${ }^{79}$

En consecuencia, esta corriente señala que sólo la objetivación sobre sí mismo es aquella que exalta la libertad del individuo para trabajar en su propia conciencia. Ello lo lleva a luchar contra las restricciones biológicas o sociales para tomar decisiones. En este sentido, para Punch! la estrategia que más se acerca a esta forma libre y racional de mejorar la toma de decisiones es Steer, pero considera como punto débil su proyecto de la Ilustración del siglo XXI como núcleo del conocimiento, emblema de la Rsa y el cual resguarda un proyecto político. ${ }^{80}$

Por último, cuestiona la eficiencia y la evidencia empírica detrás de cada una de las estrategias y cómo a partir del conocimiento pueden ser refutadas. El argumento principal de la agenda conductual es que las personas, a través de empujoncitos, deliberación o reflexión llegarán a alcanzar una madurez cognitiva con la que podrán ser autónomos en la toma de decisiones; y es este ser humano autónomo la esencia para legitimar al gobierno conductual. ${ }^{81}$ Con todo, para los críticos de este cambio, intentar cambiar

\footnotetext{
${ }^{79}$ Jones, Pykett y Whitehead, op. cit., pp. 170-171.

${ }^{80}$ Loc. cit.

81 Ibid., p. 189.
} 
el comportamiento excluyendo los puntos de vista sociológico, histórico, cultural o político que se involucran en el diseño de políticas restringe su aplicación. Punch! hace énfasis en la educación como la piedra en el zapato para los conductuales, pues la educación como proceso formativo también cambia las preferencias y comportamientos de las personas, además de que puede ser una vía de transformación en los hábitos y toma de decisiones de los individuos. Por lo tanto, debido a que la educación no es un proceso que se agota, estas estrategias no pueden llegar a ser del todo éticas o lograr empoderar a las personas en realidad.

Cabía destacar que a diferencia de las anteriores estrategias, Punch! es más bien una argumentación crítica más que instrumental. Si bien esta es una diferencia importante, vale la pena considerar esta corriente debido a que en diversas discusiones relacionadas a las teorías de Foucault está surgiendo la tendencia de no sólo criticar sino intervenir y construir alternativas. ${ }^{82}$

\section{CONCLUSIONES: POSIBILIDADES Y ADVERTENCIAS SOBRE EL} ADVENIMIENTO DEL GOBIERNO CONDUCTUAL

La discusión del gobierno intervencionista sobre los comportamientos irracionales de las personas abre nuevas posibilidades y al mismo tiempo dudas respecto de la discusión de cómo un gobierno en democracia puede conducirse para resolver problemas públicos. En un extremo tendríamos las visiones sobre optimistas de la gobernanza, ${ }^{83}$ donde la interdependencia entre muchos actores con diferentes cuotas de poder permitirían pensar una acción gubernamental necesaria y hasta racionalmente participativa. En el otro extremo, tenemos una visión en cierto sentido tecnocrática, que pone a un grupo de expertos a pensar las arquitecturas de la

82 William Walters, Governmentality, Londres, Routledge, 2012.

${ }^{83}$ David Arellano, José Sánchez y Bartolo Retana, “¿Uno o varios tipos de gobernanza? Más allá de la gobernanza como moda: la prueba del tránsito organizacional”, Cuadernos de Gobierno y Administración Pública, vol.1, núm. 2, 2014, pp. 9-29. 
decisión: los nudges. ${ }^{84} \mathrm{Al}$ respecto, cabría primero destacar que estos no necesariamente son extremos excluyentes: los nudges, como se ha descrito en este artículo, buscan intervenir en esos espacios donde las decisiones de las personas pueden no ser racionales justamente debido a factores de información, biológicos y neuronales incluso, que construyen una especie de velo de costumbres o hábitos relativamente automáticos y que las personas no podemos hacer conscientes con facilidad. En este sentido, se están añadiendo instrumentos a la caja de herramientas de la intervención gubernamental sin, necesariamente, hacer excluyentes diversas formas o instrumentos de reforma.

No obstante, es claro que como toda intervención de un aparato de autoridad -con capacidades políticas y coercitivas- la intervención gubernamental no será nunca inocua. Las críticas de propuestas como Think o Punch! dejan claro que el debate respecto de la legitimidad (y no sólo efectividad) de instrumentos como nudges requiere ser abierto. Por un lado, no hay duda de lo benéfico de añadir instrumentos de arquitectura de decisiones con miras, al menos en el discurso, claramente ligadas a generar y proporcionar información más clara, pertinente y dirigida a personas que, por diversas razones, pueden ver mejoradas sus decisiones. "Defaults" para apoyar las dinámicas de donación de órganos, diseños novedosos de reportes de alimentos o de gasto de energía para dejar claro a las personas los beneficios de una dieta saludable o un impacto ambiental controlado, son ejemplos clásicos. Una pregunta posible es si estas estrategias son, al final de cuentas, manipulaciones. ${ }^{85}$ Pensamos que es difícil plantear que lo son, al menos en un sentido estricto: las arquitecturas de decisión no tendrían por qué no ser públicas y explicadas. Es decir, nada en la propuesta de nudges habla de esconder u ocultar la explicación y las bases de su creación como prerrequisito para su efectividad. Ahora bien, es lógico que no se pretendería negar tampoco que al modificar la arquitectura de cierta decisión se está buscando aprovecharse de

${ }^{84}$ Miguel Zapata, "Expertos y libertad en el paternalismo libertario", Revista Digital Universitaria, UNAM, vol. 16, núm. 4, 2014, pp. 1-9.

${ }^{85}$ Ibid., p. 7. 
alguna tendencia psicológica o neuronal. Regresando al ejemplo del default para impulsar la donación de órganos: no afecta la eficacia del nudge el que se haga una clara explicación ex ante de la intención del mismo. La preocupación en todo caso estaría en que muchos nudges, en efecto, pueden perder su eficacia si se explican y se hacen explícitos. Pongamos por ejemplo un nudge que se utiliza para mejorar la autoestima de solicitantes de trabajo con un instrumento que se les dice a los participantes que es para medir sus capacidades. ${ }^{86} \mathrm{El}$ instrumento no mide capacidades, sino que busca elevar el optimismo natural de los seres humanos. Si se explicara el mecanismo se perdería su efectividad; e incluso los solicitantes, de saberlo ex post a su participación, seguramente podrían sentirse defraudados y manipulados. Entonces, si bien no es una condición sine qua non, la opacidad podría ser necesaria para que ciertos nudges funcionaran adecuadamente. Ese es, en realidad, un punto crítico - por poco explicado- que deben atender los defensores de los nudges.

Sin embargo, la preocupación puede hacerse más sólida, probablemente, desde dos ejes: primero, si los nudges se pueden convertir en una vía fácil, evitando con ello realizar mayores esfuerzos por debatir y racionalizar las diferentes visiones y posiciones de las personas en una sociedad plural; y, segundo, el factor social y político de enfatizar con demasiada confianza un mecanismo paternalista y técnico que se diseña por grupos de expertos e iniciados que olvidan la socialidad de los procesos humanos. La idea de Think, en efecto, parece preocuparse justamente porque los nudges se conviertan en camino fácil, en una estrategia dominante más que en lo que parecen ser: instrumentos parciales, pequeños, de alcance limitado y que pueden utilizarse más bien como medio de un fin mayor. En otras palabras, el reto es cuidar que los nudges no sean una vía fácil, tecnocrática -que se resigna a la incapacidad de los seres humanos a ser racionales en sus decisiones-, en vez de seguir intentando formar mecanismos, instrumentos; asambleas que insistan en buscar comprender mejor cómo las decisiones se toman como sociedad y como individuos en una democracia plural.

${ }^{86}$ Frank Mols et al., op. cit., p. 87. 
El segundo eje de preocupación, en algún sentido relacionado con los argumentos de Punch!, es que no se puede evitar pensar que los gobiernos son criaturas sociales y políticas. Para comenzar, ¿qué lógica política concreta, qué dinámica técnico-administrativa, qué cultura organizacional se forma en las oficinas de los encargados de los nudges? ¿Es una suerte de visión de grupo cerrado, de expertos e iniciados en teorías neuroeconómicas pensando nuevos experimentos comportamentales para medir e identificar mejor cómo los desvalidos seres humanos comunes se equivocan inevitablemente? Puede ser esta una caricatura injusta, pero los estudios de cómo los grupos de expertos toman decisiones y organizan dinámicas cerradas y cada vez más aisladas de otras personas (que piensan distinto, por ejemplo) son muy claros al respecto de su alta propensión a ocasionar terribles consecuencias. ${ }^{87}$ La socialidad y la política concreta de cómo los nudges se piensan y aplican en situaciones y contextos concretos no pueden escapar al análisis, si se desea evitar el encumbramiento tecnocrático de diseñadores aislados de nudges como instrumento de gestión pública.

Con todo, más allá de la socialidad y la dinámica política de las oficinas gubernamentales que piensan e implementan nudges, está la idea del modelo de sociedad que una política de este tipo imagina y, por tanto, reproduce (probablemente la más fuerte preocupación de Punch!). Una sociedad de individuos, en el fondo, incapaces de controlar su propia racionalidad y que, en consecuencia, deben explorar su propia lógica, internamente, con muchos límites insalvables. No incorporar elementos críticos que han funcionado generalmente para lidiar con dichas limitaciones, como la internalización de normas o las construcciones de identidad compartida ${ }^{88}$ puede producir, sin duda, efectos no buscados (como expusimos con el caso del examen pro-optimismo, vid. supra), y constructos políticos éticamente dudosos -ante la opacidad y secretismo que podrían requerir para su utilización efectiva-. La moda ha llegado, pero el debate apenas comienza. Este trabajo es

87 Por ejemplo, el famoso groupthink estudiado por Irving Janis, Victims of Groupthink, Boston, Houghton Mifflin, 1972.

${ }^{88}$ Mols et al., op. cit. 
una invitación para plantear más preguntas y abrir la discusión crítica evitando lo que ha pasado con diversas corrientes de la administración y las políticas públicas: se ven primero y optimistamente sus ventajas, pero poco sus desventajas.

\section{BiBLIOGRAFÍA}

Aguilar, Luis F., Gobernanza y gestión pública, México, FCE, 2006.

Arellano, David, José Sánchez y Bartolo Retana, “¿Uno o varios tipos de gobernanza? Más allá de la gobernanza como moda: la prueba del tránsito organizacional", Cuadernos de Gobierno y Administración Pública, vol.1, núm. 2, 2014, pp. 9-29.

Ariely, Dan, The Upside of Irrationality, Nueva York, Harper, 2010.

Barzelay, Michael, Breaking through Bureaucracy, Berkeley, University of California Press, 1992.

Behavioural Insights Team, "EAST: Four Simple Ways to Apply Behavioural Insights", Londres, 2014, en: http://38r8om2xjhhl25mw24492dir. wpengine.netdna-cdn.com/wp-content/uploads/2015/07/BIT-Publication-EAST_FA_WEB.pdf

, "Applying Behavioural Insights to Organ Donation", Londres, n. d., en: http://www.behaviouralinsights.co.uk/sites/default/files/ Applying_Behavioural_Insights_to_Organ_Donation_report.pdf

Bor, Daniel, The Ravenous Brain, Nueva York, Basic Books, 2012.

Brunsson, Nils, Mechanisms of Hope: Maintaining the Dream of the Rational Organization, Copenague, Copenhagen Business School Press, 2006. - y Johan Olsen, The Reforming Organization, Oslo, Fagbokforlaget, 1993.

Cartwrite, Nancy y Jeremy Hardie, Evidence-Based Policy: A Practical Guide to Do It Better, Oxford, Oxford University Press, 2012.

Compston, Hugh, Policy Networks and Policy Change: Putting Policy Network Theory to Test, Nueva York, Palgrave, 2009.

Dennett, Daniel, Intuition Pumps and Other Tools of Thinking, Nueva York, Norton \&Co, 2013. -, Freedom Evolves, Nueva York, Penguin Books, 2003.

Dolan et al., Mindspace: Influencing behavior through Public Policy, Reino Unido, Cabinet Office, 2010. 
Dolan, Paul, "Influencing the Financial Behavior of Individuals: The Mindspace Way", en A. Oliver (ed.), Behavioral Public Policy, Cambridge, Cambridge University Press, 2013, pp. 191-208.

Eagleman, David, Incognito: The Secret Lives of the Brain, Nueva York, Pantheon, 2011.

Elster, Jon, Salomonic Judgments: Studies in the Limitations of Rationality, Cambridge, Cambridge University Press, 1989.

Fiedler, Klaus, "Voodoo Correlations Are Everywhere. Not Only on Neouroscience”, Perspectives on Psychological Science, vol. 6, núm. 2, 2011, pp. 163-171.

Gigerenzer, Gerd, Gut Feelings: The Intelligence of the Unconscious, Nueva York, Penguin, 2007.

—, Reckoning with Risk: Learning to Live with Uncertainty, Nueva York, Penguin, 2002.

Glimcher, Paul, Foundations of Neuroeconomic Analysis, Oxford, Oxford University Press, 2011.

Halpern, David et al., Personal Responsibility and Changing Behavior: The State of Knowledge and Its Implications for Public Policy, Londres, Strategy Unit, 2004, 70 pp.

Harris, Sam, Free Will, Nueva York, Free Press, 2002.

Hatry, Harry, Performance Measurement: Fashions and Fallacies, Public Performance and Management Review, vol. 254, núm. 4, 2002, pp. 352-358.

Haynes, Laura et al., "Test, Learn, Adapt: Developing Public Policy with Randomised Controlled Trials", Londres, Behavioural Insights Team, 2012, en: https://www.gov.uk/government/publications/test-learnadapt-developing-public-policy-with-randomised-controlled-trials

Hutson, Matthew, The Seven Laws of Magical Thinking, Nueva York, Hudson Street P., 2012.

Jackson, Brad, Management Gurus and Management Fashions, Londres, Routledge, 2001.

Janis, Irving, Victims of Groupthink, Boston, Houghton Mifflin, 1972.

John, Peter, G. Smith y G. Stoker, "Nudge Nudge, Think Think: Two Strategies for Changing Civic Behaviour", The Political Quarterly, vol. 80, núm. 3, julio-septiembre de 2009, pp. 361-370.

John, Peter, Sarah Cotterill, Alice Moseley, Liz Richardson, Graham Smith, Gerry Stoker y Corinne Wales, Nudge, Nudge, Think Think. Ex- 
perimenting with the Ways to Change Civic Behavior, Londres, Bloomsbury, 2011.

Jones, R., J. Pykett y M. Whitehead, Changing Behaviours: On the Rise of the Psychological State, Cheltenham, Edward Elgar, 2013.

Kahneman, Daniel, Pensar rápido, pensar despacio, México, Debate, 2012.

Knott, David et al., Achieving Culture Change, Londres, Cabinet Office, 2008.

Lehrer, Jonah, How We Decide, Boston, Mariner, 2009.

Libet, Benjamin, "Unconscious Cerebral Initiative and the Role of Conscious Will in Voluntary Action", Behavioral and Brain Sciences, vol. 8, 1985, pp. 529-566.

Lynn, Laurence Jr., Public Management: Old and New, Nueva York, Routledge, 2006.

Mitchell, Gregory, "Libertarian Paternalism Is an Oxymoron", Northwestern University Law Review, vol. 99, núm. 3, 2005.

Mols, Frank et al., "Why a Nudge Is Not Enough: A Social Identity Critique of Governance by Stealth", European Journal of Political Research, vol. 54, núm. 1, 2014, pp. 81-98.

Montague, Read, How We Make Decisions, Nueva York, A Plume Book, 2006.

Oliver, Adam, "Nudging, Shoving and Budging: Economic-Informed Policy”, Public Administration, vol. 3, núm. 3, 2015, pp. 700-714.

Pfaff, Donald, The Neuroscience of Fair Play, Nueva York, Dana Press, 2007.

Pinker, Steven, The Blank Slate: The Modern Denial of Human Nature, Nueva York, Penguin Books, 2002.

Pollit, Christopher, "Justificactions by Work or by Faith: Evaluating the New Public Management", Evaluation, vol. 1, núm. 2, 1995.

Rose, Nikolas y Joelle Abi-Rached, Neuro: The New Brain Sciences and the Management of the Mind, Princeton, Princeton University Press, 2013.

Rowson, Jonathan, Transforming Behavior Change: Beyond Nudge and Neuromania, Londres, RSA, 2011.

Satel, S. y S. O. Lilienfeld, Brainwashed: The Seductive Appeal of Mindless Neuroscience, Basic Books, 2013.

Simon, Herbert, Administrative Behavior, Chicago, Chicago University Press, 1947.

Smith, David, Why We Lie, Nueva York, St. Martin's Griffin, 2004. 
Smith, Peter, Measuring Outcome in the Public Sector, Exeter, Taylor \& Francis, 1996.

Sunstein, Cass R., "The Ethics of Nudging”, Social Science Research Network Working Paper Series, Discussion paper no. 806, Harvard, 2014.

- Simpler. The Future of Government, Nueva York, Simon \& Shuster, 2013.

Tallis, Raymond, Aping Mankind, Durham, Acumen, 2011.

Thaler, Richard y Cass Sunstein, Nudge: Improving Decisions about Health, Wealth, and Happiness, Nueva York, Penguin Books, 2008.

Trivers, Robert, The Folly of Fools, Nueva York, Basic Books, 2011.

Tversky, Amos y Daniel Kahneman, "The Framing of Decision and the Psychology of Choice”, Sciences, New Series, vol. 21, núm. 4881, 1981, pp. 453-458.

Van der Heijden, Jeroen y Mark Kosters, "From Mechanism to Virtue: Evaluating Nudge-Theory", RegNet Research Papers, núm. 80, Regulatory Institution Network, 2015.

Vul, Edward, Christine Harris, Piotr Winkielman y Harold Pasher, "Puzzlingly High Correlations in fMRI Studies of Emotion, Personality, and Social Cognition", Perspectives on Psychological Science, vol. 4, núm. 3, 2009, pp. 274-290.

Walters, William, Governmentality, Londres, Routledge, 2012.

Whitehead, Mark et al., Nudging All over the World, Reino Unido, Economic and Social Research Council, 2014.

Whitfield, John, People Will Talk, Nueva Jersey, John Wiley \& Sons, 2012.

Wilson, Edgar, Sociobiology: The New Synthesis, Nueva York, Belknap Press, 2000.

Wright, Robert, The Moral Animal, Nueva York, Vintage, 1994.

Zak, Paul J., "The Physiology of Moral Sentiments", Journal of Economic Behavior Ẽ Organization, vol. 77, núm. 1, 2011, pp. 53-65.

(ed.), Moral Markets, Princeton: Princeton University Press, 2008.

Zapata, Miguel, "Expertos y libertad en el paternalismo libertario", Revista Digital Universitaria, unAM, vol. 16, núm. 4, 2014, pp. 1-9. 